\title{
Water-soluble chitosan preparation from marine sources
}

\author{
Yatim Lailun Ni'mah*, Harmami Harmami, Ita Ulfin, Suprapto Suprapto, Clarissa Welny Saleh \\ Department of Chemistry, Faculty of Sciences, Institut Teknologi Sepuluh Nopember (ITS), Kampus ITS Sukolilo, Surabaya 60111, Indonesia \\ * Corresponding author: yatimnikmah@gmail.com
}

\section{Article history}

Received 10 January 2018

Revised 15 March 2018

Accepted 20 May 2018

Published Online 14 April 2019

\section{Graphical abstract}

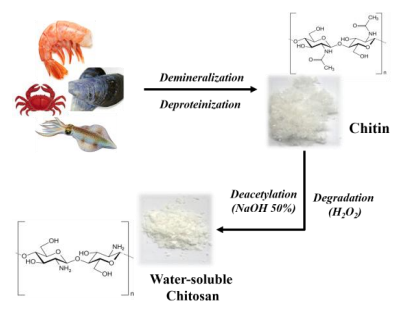

\begin{abstract}
Water-soluble chitosan (WSC) has been derived from different marine sources such as squid pen, shrimp, mussel, and crab shells. Chitosan was obtained by deacetylation of chitin. Degradation of chitosan by hydrogen peroxide would produce WSC. Demineralization process was optimized by varying incubation time and temperature to minimize the mineral content in chitin. WSC that obtained was characterized by Fourier-transform infrared spectroscopy (FTIR) to calculate the deacetylation degree. Deacetylation degree of WSC was also studied by titrimetric method. The ash content of chitin from marine sources was measured to obtain the optimum demineralization incubation time. The optimum incubation time for demineralization process was 12 hours and stirred at $50 \mathrm{rpm}$. Recovery and deacetylation degree of WSC were found to be varied and depended on the source of WSC. Each sample of WSC from shrimp shell, mussel shell, squid pen and crab shell has the degree of deacetylation of $64.18 \%, 35.03 \%, 58.04 \%$ and $53.91 \%$ respectively. The presence of amine group was confirmed from FTIR spectra ofsynthesized WSC.
\end{abstract}

Keywords: Deacetylation, degradation, FTIR, water-soluble chitosan

\section{INTRODUCTION}

Chitin is one of the most abundant biopolymers that can be isolated from living organism especially from crustaceans, insects, and fungi. Chitin is a polymer of $\beta-1,4-N$-acetylglucosamine and forms a straight chain polymer (Kim, 2010). Based on its crystalline structure, chitin that found in crustaceans and fungi is classified into $\alpha$-chitin, $\beta$-chitin, and $\gamma$-chitin. $\alpha$-Chitin is the piles of chitin chains that are arranged antiparallel and can be found in the shell of crustacean such as crab shell and shrimp shell. $\beta$-Chitin has crystalline structure where all of the chains piles are arranged parallelly. $\beta$-chitin can be isolated from squid pens, while $\gamma$-chitin can be found in fungi and yeast (Jang et al., 2004). Chitin has poor solubility, in which it is insoluble in most common solvents. This solubility problem of chitin renders limitation in its application and utilization.

Crustaceans that captured from both marine and inland waters are about 6.1 million tons (FAO, 2010). Food consumption from marine sources can produce waste for about $40-50 \%$ of total mass. The produced waste contains about $40 \%$ of chitin along with calcium carbonate (Arbia et al., 2013). This amount of chitin in waste is a promising source for chitin and chitin derivatives product. The extraction of chitin from crustaceans requires removal of protein, minerals, and pigments. Since there is no standard method for chitin extraction, many studies of chitin extraction methods have been conducted to obtain pure chitin without changing the physicochemical properties of chitin (Gortari and Hours, 2013).

Chitosan is a deacetylated derivate of chitin and consists of straight-chain biopolymer of D-glucosamine and $\mathrm{N}$-acetyl-Dglucosamine. Chitosan is one of biopolymers that has a similar structure to cellulose (Abdou et al., 2008). Bioactivity, biodegradability, fibre-grade properties, and coating ability of chitosan have enabled chitosan to be a suitable material for corrosion control. Chitosan has been applied for corrosion inhibitor and coating material for several metal-based pipes (Alsabagh et al., 2014; Cheng et al., 2007; Riszki and Harmami, 2015; Saleh et al., 2017), medical and pharmaceutical applications (Dodane and Vilivalam, 1998), antibacterial and preservative in food industry (Vargas and GonzálezMartínez, 2010), cosmetic industry (Lang and Clausen, 1989), agriculture, and environmental protection (Gooday, 1977). Chitosan is generally obtained from the extraction of chitin found in crustacean shells and deacetylated by using chemical or through enzymatic deacetylation. Both chitin and chitosan are biodegradable and nontoxic (Younes and Rinaudo, 2015).

Chitosan is only soluble in aqueous acidic solution and insoluble in water or organic solvent. Its crystalline structure is formed by strong hydrogen bonding between acetamide group, hydroxyl group, and carbonyl group, which preventing chitosan to be soluble in water or organic solvent (Vachoud et al., 2012). Since its solubility properties have limited chitosan in certain applications solubility enhancement of chitosan has been done by various methods including salt derivation of chitosan (Kim et al., 1997), surfactant derivation of chitosan (Pepić et al., 2010), and decrement in molecular weight of chitosan (No et al., 2002). Several research on degradation of chitosan which could decrease its molecular weight have been reported. Chemical and physical methods for chitosan degradation were also introduced, including ultraviolet and gamma radiations (Wasikiewicz et al., 2005), thermal degradation (Gámiz-González et al., 2017), oxidative degradation (Zhao et al., 2009), and hydrolytic degradation (Horton, 2013). Biochemical method for chitosan degradation including enzymatic degradation has been proceeded to be the most effective method which resulted in no changes of the structural and properties of chitosan but at the same time it is an expensive approach (Kim and Rajapakse, 2005). Oxidative degradation using oxidative chemical such as Peroxotungstate (Ma et al., 2014), or using catalyst such as $\mathrm{Fe}^{2+}$ or heteropoly acid has been reported as efficient way to degrade chitosan. Otherwise, application of hydrogen peroxide as 
oxidative degradation agent has been reported to be the most effective, inexpensive and enviromental-friendly method to degrade chitosan chain (Du et al., 2009).

This research was focused on a study of chitin and water-soluble chitosan (WSC) extracted from different marine sources. Chitin was extracted from squid pen, shrimp, mussel, and crab shell via demineralization and deproteinization treatments using $\mathrm{HCl}$ and $\mathrm{NaOH}$ respectively. Optimization of demineralization treatment was carried out to determine the optimum incubation time and condition. Hydrogen peroxide was used to degrade the crude chitosan into WSC. The differences of chitin and WSC from different sources were investigated using FTIR spectroscopy.

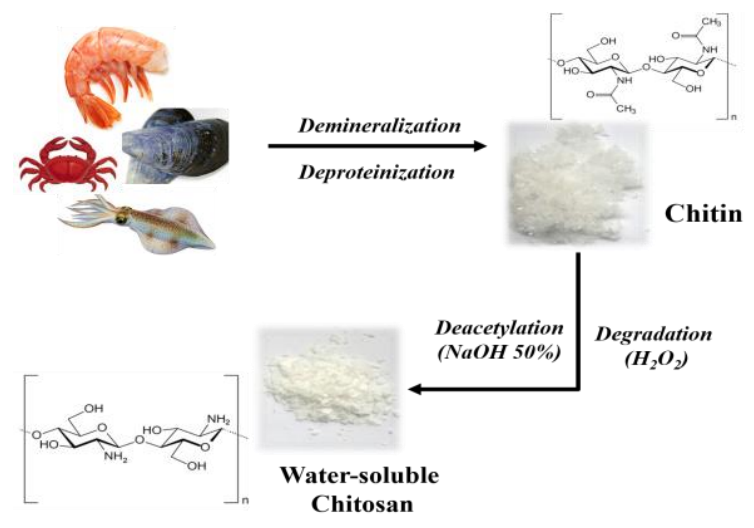

Figure 1 Schematic diagram for preparation of water-soluble chitosan from different marine sources.

\section{EXPERIMENTAL}

\section{Materials}

The starting materials (squid pens, shrimp shell, mussel shell, and crab shells) were collected from a seafood processing factory in Gresik, Jawa Timur Indonesia. The starting materials were pulverized separately in a mill and screened through a 40-mesh sieve.

\section{Reagents}

Hydrochloric acid $(\mathrm{HCl}, 37 \%)$, sodium hydroxide $(\mathrm{NaOH}$, $99.99 \%)$, acetic acid $\left(\mathrm{CH}_{3} \mathrm{COOH}, 100 \%\right)$, hydrogen peroxide $\left(\mathrm{H}_{2} \mathrm{O}_{2}\right.$, $30 \%)$ and ethanol $\left(\mathrm{C}_{2} \mathrm{H}_{5} \mathrm{OH}, 99.99 \%\right)$ were used and purchased from Merck, Germany. Demineralized water was used for chemical preparation.

\section{Solutions preparation}

$100 \mathrm{~mL}$ of $2 \mathrm{M} \mathrm{HCl}(\mathrm{v} / \mathrm{v})$ solution was made by dissolving 16.67 $\mathrm{mL} \mathrm{HCl} 37 \%$ with aqua demineralization in $100 \mathrm{~mL}$ volumetric flask.

$100 \mathrm{~mL}$ of $50 \% \mathrm{NaOH}(\mathrm{w} / \mathrm{w}$ and density of $50 \% \mathrm{NaOH}$ was 1.53 $\mathrm{g} / \mathrm{mL}$ ) solution was made by dissolving $76.5 \mathrm{~g} \mathrm{NaOH}$ pellets (Merck, $99.99 \%$ ) with aqua demineralization in a $100 \mathrm{~mL}$ volumeric flask.

$100 \mathrm{~mL}$ of $2 \% \mathrm{CH}_{3} \mathrm{COOH}(\mathrm{v} / \mathrm{v})$ solution was made by diluting $6.67 \mathrm{~mL}$ of $\mathrm{CH}_{3} \mathrm{COOH}$ (SAP chemicals, 30\%) solution with aqua demineralization in a $100 \mathrm{~mL}$ volumeric flask.

\section{Chitin extraction}

In a typical experiment, 50 gram of powder sample (shrimp, mussel, crab shells or squid pens) with 40 mesh was immersed in $2 \mathrm{M}$ $\mathrm{HCl}$. The incubation time in demineralization treatment was varied between 4-24 hours at room temperature with static condition and stirred at $50 \mathrm{rpm}$. Then the residue of filtration was immersed in $2.5 \mathrm{M}$ $\mathrm{NaOH}$ at $60^{\circ} \mathrm{C}$. The residue obtained was then washed with demineralized water and absolute ethanol. In order to remove water content, chitin was dried at $50^{\circ} \mathrm{C}$.

\section{Synthesis of water-soluble chitosan}

Chitin that extracted from previous steps was put into $50 \% \mathrm{NaOH}$ at $60{ }^{\circ} \mathrm{C}$. Dry residue was added into $2 \%(\mathrm{w} / \mathrm{w})$ acetic acid. $30 \% \mathrm{H}_{2} \mathrm{O}_{2}$ was added to the solution and the solution was left to be reacted for 4h. Ethanol was then added to solution after reaction. Solution was dried in air oven at $50^{\circ} \mathrm{C}$ to obtain solid WSC. The recovery of chitin and WSC (\%) was calculated using equation (1).

$$
\% \text { Recovery }=\frac{\text { weight of chitin } / \text { WSC }}{\text { weight of sample }} \times 100 \%
$$

Chitin and WSC obtained were characterized with Fourier-transform infrared spectroscopy (Shimadzu FTIR-8400S). Deacetylation Degree (\%DD) of WSC was measured by using titrimetric method (Czechowska-Biskup et al., 2012).

\section{Measurement of ash content}

Chitin sample of 1 gram was heated from room temperature to $500^{\circ} \mathrm{C}$ in 1 hour. The sample was continued to be heated to $750^{\circ} \mathrm{C}$ in 1 hour and held at $750^{\circ} \mathrm{C}$ for 2 hours. The ash content was calculated from the weight of ash residue and divided by the initial sample weight.

\section{RESULTS AND DISCUSSION}

\section{Recovery of chitin and water-soluble chitosan}

Chitin in different samples from marine sources were extracted through the demineralization and deproteinization steps and then the extracted chitin was reacted with $\mathrm{NaOH}$ to produce chitosan (deacetylation stage). Chitosan obtained was then reacted with $\mathrm{H}_{2} \mathrm{O}_{2}$ to produce WSC. The reaction was took place as shown in Figure 2.

Improvement of chitosan solubility has been conducted from the very first treatment since it was important to make sure that the chitosan was free from residual mineral, protein or pigment which could cause side effects on its solubility, as well as on its biological properties. Particle size of grounded sample (shrimp shell, mussel shell, crab shell, and squid pens) could affect the penetration of hydrochloric acid and sodium hydroxide solution into the chitin matrix (Truong et al., 2007). Because of that, grounding the sample into small and uniform size was important prior to the next treatments.

Mineral content in chitin and chitosan would give contribution in chitin and chitosan pureness, as well as in their solubility properties in water. Controlling mineral content could be done by optimizing demineralization process. Optimization of incubation time in demineralization treatments was conducted in $4,8,12$, and 24 hours incubation time with $2 \mathrm{M} \mathrm{HCl}$. The incubation condition was fixed to be in both static and stirring condition with stirring speed at 50rpm. The ash contents of chitin from different incubation time and condition in demineralization treatment were shown in Table 1.

Table 1 Ash Content (\%) of chitin from marine sources in different demineralization incubation time and condition.

\begin{tabular}{|l|l|l|l|l|l|}
\hline \multicolumn{2}{|c|}{ Incubation time } & \multicolumn{1}{c|}{$\begin{array}{c}4 \\
\text { (hours) }\end{array}$} & $\begin{array}{c}\text { 8 } \\
\text { (hours) }\end{array}$ & $\begin{array}{c}12 \\
\text { (hours) }\end{array}$ & $\begin{array}{c}24 \\
\text { (hours) }\end{array}$ \\
\hline \multirow{2}{*}{$\begin{array}{l}\text { Shrimp } \\
\text { shell }\end{array}$} & Static & 21.14 & 11.23 & 7.22 & 6.98 \\
\cline { 2 - 6 } & Stirring & 17.91 & 9.64 & 6.11 & 3.20 \\
\hline $\begin{array}{l}\text { Mussel } \\
\text { shell }\end{array}$ & Static & 29.37 & 14.69 & 6.31 & 6.19 \\
\cline { 2 - 6 } & Stirring & 25.88 & 13.09 & 5.71 & 4.94 \\
\hline \multirow{2}{*}{$\begin{array}{l}\text { Squid } \\
\text { pen }\end{array}$} & Static & 2.37 & 1.39 & 0.79 & 0.75 \\
\cline { 2 - 6 } & Stirring & 1.94 & 0.91 & 0.75 & 0.66 \\
\hline \multirow{2}{*}{$\begin{array}{l}\text { Crab } \\
\text { shell }\end{array}$} & Static & 31.55 & 16.57 & 7.12 & 5.98 \\
\cline { 2 - 6 } & Stirring & 28.53 & 13.20 & 5.99 & 3.22 \\
\hline
\end{tabular}

Data in Table 1 shows that the mineral content (indicated as ash content) in chitin was decreased along with the length of the incubation period in the demineralization process. Inadequate mineral content reduction could be seen at incubation time of 12 hours to 24 hours for all chitin sources. This result indicated that 12 hours incubation time was the optimum time for the incubation of the sample in the demineralization treatment. Although 24 hours of incubation time could give the lesser amount of ash content, it also showed that solution has started to be saturated. Static and stirring conditions could also give different results in ash content. Stirring condition would give lesser ash content than static condition, 
indicating that reaction between insoluble mineral in sample and dilute $\mathrm{HCl}$ has became more effective with help of stirring condition. This result was applied to all sources of chitin. Longer incubation time with dilute $\mathrm{HCl}$ in demineralization time could cause uncontrolled polymer degradation of chitin. Combination of long incubation time and stirring condition could change the physico-chemical properties of chitin obtained. In conclusion, sample demineralization optimation with one-time incubation in dilute $\mathrm{HCl}$ at low stirring speed has produced chitin with less ash content. Mineral content in chitin could affect the molecular weight and deacetylation degree (Percot et al., 2003). Mineral content was also contributed to the solubility and biological activity of chitin and chitosan. Since it was difficult to produce free mineral chitin, it was important to produce chitin with low mineral content as possible.

According to Du et al. (2009), the high average molecular weight of chitosan would cause low solubility of chitosan in water. The decrement in molecular weight of chitosan molecules by cutting the chains of chitosan polymer to be shorter could increase the solubility of chitosan in water. Chitin obtained from optimized demineralization process (incubation time of 12 hours and with stirring condition) and deproteinization process was then reacted with $\mathrm{NaOH} 50 \%$ as deacetylation process was continued by chitosan polymer degradation process using $\mathrm{H}_{2} \mathrm{O}_{2}$ to obtain WSC. This general reaction was shown in Figure 2. Based on the obtained results from WSC synthesis, a fine, white solid that dissolved in water was obtained. Chitin and WSC obtained were shown in Figure 3.
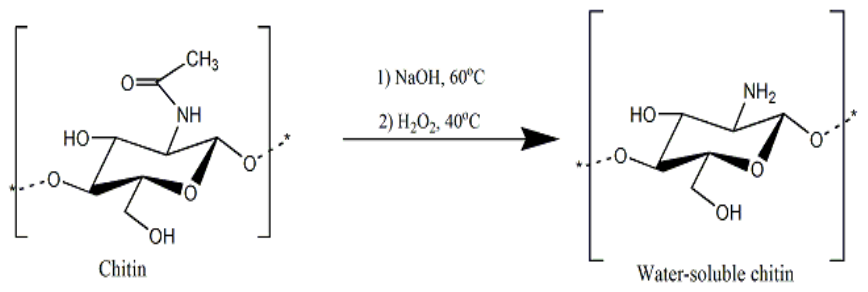

Figure 2 Reaction synthesis of Water Soluble Chitosan.

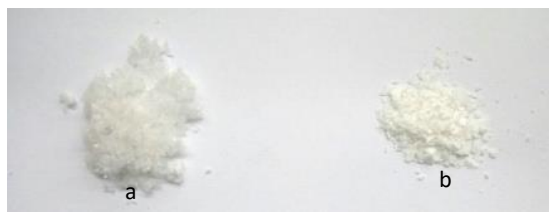

Figure 3 The result of (a) chitin extraction and (b) the synthesis of WSC.

The recovery percentages of chitin and WSC from several marine sources were calculated and shown in Table 2. The two highest recovery values of WSC were from squid pen by $37.87 \%$ and shrimp shell by $16.79 \%$.

Table 2 Recovery of chitin and WSC from different sources.

\begin{tabular}{lrr}
\hline \multicolumn{1}{c}{ Source } & $\begin{array}{r}\text { Chitin Recovery } \\
(\%)\end{array}$ & $\begin{array}{r}\text { WSC Recovery } \\
(\%)\end{array}$ \\
\hline Shrimp shell & 28.88 & 16.79 \\
Mussel shell & 16.35 & 4.19 \\
Squid pen & 47.07 & 37.87 \\
Crab shell & 19.33 & 5.48 \\
\hline
\end{tabular}

Many studies on extraction of chitin and chitosan have been reported that recovery of chitin and chitosan was differed between one crustacean to another. Hajj et al. (2014) estimated that the recovery percentages for chitin from shrimp shell $(19.13 \%)$ and crab shell (20.80\%), while for chitosan from shrimp shell (14.90\%) and crab shell (5.30\%). Abdulkarim et al. (2013) calculated the recovery percentages of chitin and chitosan in mussel shell were $23.25 \%$ and $15.14 \%$ respectively. Chandumpai et al. (2004) reported that squid pen contained $36.06 \%$ of chitin and could be converted to chitosan with yield of $77.55 \%$. In this present study, recovery values of chitin and WSC were found to be differed and depended on the species of chitin sources. Physical appearances of chitin and WSC obtained in this study were white to slightly yellow powder, which were in accordance with physical appearances shown by chitin and WSC from all marine sources.

\section{Deacetylation degree of water-soluble chitosan}

Deacetylation degree of WSC from different sources was determined using titrimetric method reported by Czechowska-Biskup et al. (2012). WSC which contains amino groups as base will react with known and exact amount of $\mathrm{HCl}$ solution. The remained excess of $\mathrm{HCl}$ was then titrated with $\mathrm{NaOH}$ solution. As indicated in Table 3, deacetylation degrees of WSC from different sources were found to be varied. All WSC obtained in this work were partially soluble in water (Deacetylation degree was more than 50\%). The Deacetylation degree value would indicate the number of primary amine groups in WSC in which the amine group is one of th groups presented in the WSC. WSC from shrimp shell has the highest value of deacetylation degree which caused it to be more soluble in water.

Table 3 Deacetylation degree of WSC from different sources.

\begin{tabular}{cc}
\hline Source & \%DD WSC \\
\hline Shrimp shell & 64.18 \\
Mussel shell & 35.03 \\
Squid pen & 58.04 \\
Crab shell & 53.91 \\
\hline
\end{tabular}

The differences in crustacean species and extraction methods could cause different values of DD (No and Hur, 1998). Therefore, both squid pen and shrimp shell could be used as promising and renewable source of WSC.

\section{FTIR spectral analysis of chitin and water-soluble chitosan}

FTIR spectra of chitin were shown in Figure 4. FTIR spectra of chitin from different sources shown specific peaks that were indicated for the functional groups presented in chitin structure, such as 3530, 3462,3529 and $3394 \mathrm{~cm}^{-1}$ band which were corresponded to the stretching vibrational of the hydroxyl groups $(-\mathrm{OH})$.

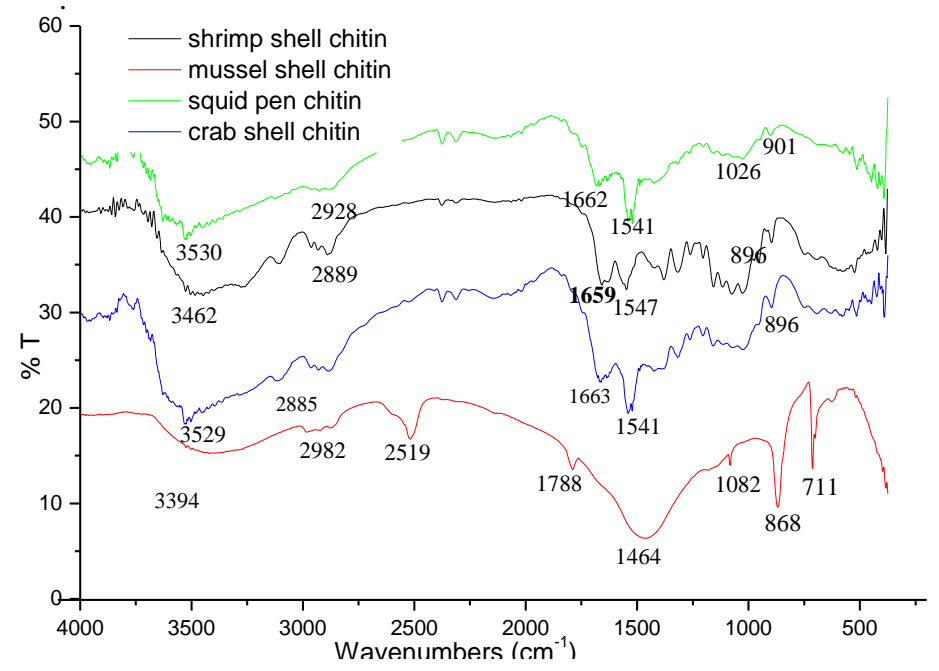

Figure 4 FTIR spectra of chitin from different sources.

Peaks at 2928, 2889, 2885 and $2892 \mathrm{~cm}^{-1}$ were indicated for $\mathrm{C}-\mathrm{H}$ $\mathrm{sp}^{3}$ vibration. It was found that FTIR characteristic peaks for chitin were appeared at around $1660 \mathrm{~cm}^{-1}, 1550 \mathrm{~cm}^{-1}$, and $900 \mathrm{~cm}^{-1}$ (amide I, II, III bonds) (Brugnerotto et al., 2001). FTIR spectra of mussel shell showed peaks at $1788 \mathrm{~cm}^{-1}$ and $1464 \mathrm{~cm}^{-1}$ which were indicated for amide I and amide II bonds, respectively (Ramasamy et al., 2014). 


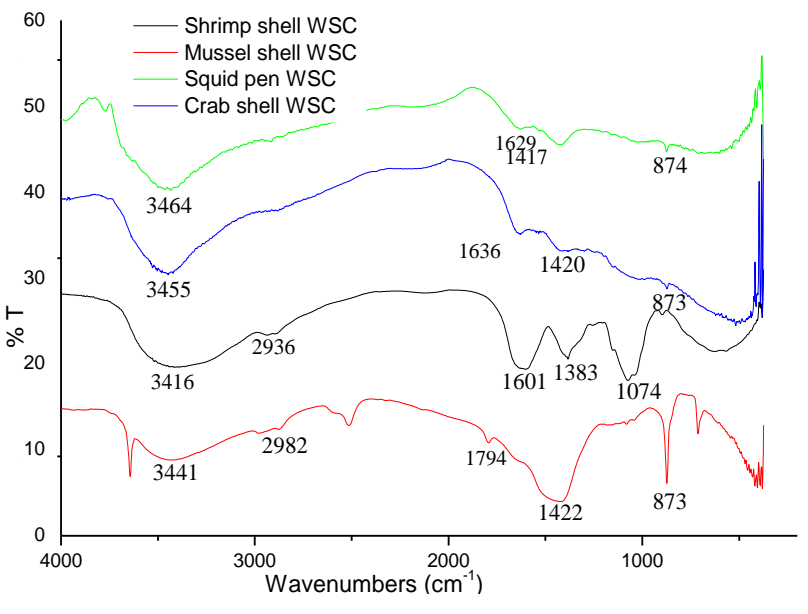

Figure 5 FTIR spectra of WSC from different sources.

FTIR spectra of WSC were shown in Figure 5 It was found that FTIR characteristic changes of peaks for chitosan were are appeared at around $1620 \mathrm{~cm}^{-1}\left(-\mathrm{NH}_{2}\right.$ primer) and $1400 \mathrm{~cm}^{-1}$ (amide deformation) at for shrimp shell, squid pen and crab shell of WSC spectra. FTIR spectra of mussel shell showed peaks at $1794 \mathrm{~cm}^{-1}$ and $1422 \mathrm{~cm}^{-1}$ which were indicated for amide deformation (Ramasamy et al., 2014).

In contrast to the FTIR spectra of chitin, FTIR spectra of WSC has no absorption peaks at 3263; 3103; 1658 and $1553 \mathrm{~cm}^{-1}$ because of the amide group that has been totally lost by another deacetylation reaction. Meanwhile, the peak at around $1400 \mathrm{~cm}^{-1}$ was appeared which represented the peak of the primary $\mathrm{N}-\mathrm{H}$ vibration formation. Comparison between the FTIR spectra of chitin and WSC could prove that the chitin deacetylation reaction was successful and produced chitosan (WSC).

The FTIR spectra of chitin and WSC in this study (as sample) were compared with IR spectra from Brugnerotto et al., 2001 (as comparation). This comparisan was performed to validate that the obtained compounds were chitin and chitosan from shrimp shell. The comparison of significant peak wave numbers in chitin and chitosan was shown in Table 4.

Table 4 Comparison of significant peak wave numbers in chitin and chitosan of shrimp shell FTIR spectra (Brugnerotto et al., 2001).

\begin{tabular}{|l|c|c|c|c|}
\hline \multirow{2}{*}{ Vibration } & \multicolumn{4}{|c|}{ Wave number $\left(\mathrm{cm}^{-1}\right)$} \\
\cline { 2 - 5 } & \multicolumn{3}{|c|}{ chitin } & \multicolumn{2}{c|}{ chitosan } \\
\cline { 2 - 5 } & Sample & comparation & Sample & comparation \\
\hline$-\mathrm{OH}$ & 3462 & 3436 & 3416 & 3450 \\
\hline $\mathrm{C}-\mathrm{H} \mathrm{sp}{ }^{3}$ & 2889 & 2925 & 2936 & 2877 \\
\hline $\mathrm{C}=\mathrm{O}$ & 1659 & 1661 & - & - \\
amida & & & & - \\
\hline $\mathrm{N}-\mathrm{H}$ & 1557 & 1558 & - & \\
amida & 1381 & 1315 & & 1420 \\
\hline $\mathrm{N}-\mathrm{H}$ & - & - & 1383 & \\
primer & & & & 1072 \\
\hline $\mathrm{C}-\mathrm{O}-\mathrm{C}$ & 1074 & 1074 & 1074 & 1023 \\
& 896 & 1029 & - & \multicolumn{4}{|c}{} \\
\hline
\end{tabular}

Based on comparison results of FTIR spectra for chitin and WSC in Table 4, it could be concluded that WSC was successfully synthesized in this study.

\section{CONCLUSION}

Water-soluble chitosans (WSC) from several marine sources were successfully synthesized. Synthesis of WSC was started from extraction of chitin from marine sources which consisted of shrimp shell, mussel shell, squid pen and crab shell. Chitin was obtained from demineralization and deproteination process. Optimization of incubation time and condition in demineralization process could conclude that optimum time of incubation sample in $2 \mathrm{M} \mathrm{HCl}$ was 12 hours with stirring speed of 50rpm. This optimum condition would give lesser mineral content in chitin. Recovery percentages of WSC based on dry sample were found to be varied by $4.19-37.87 \%$ with DD values that were varied by $35.03-64.18 \%$. Differences in recovery percentage and DD value were due to differences in chitin sources. Both shrimp shell and squid pen could be the promising sources of WSC for commercial and industrial use due to the highest recovery percentage of WSC and the abundant availability of raw materials.

\section{ACKNOWLEDGEMENT}

The financial supports from the Institute for research and community services (LPPM, Lembaga Penelitian dan Pengabdian Masyarakat) ITS (726/PKS/ITS/2017), and the facilities supports from Chemistry Department, Faculty of Mathematic and Natural Sciences, Institut Teknologi Sepuluh Nopember Surabaya (ITS) were acknowledged by the authors.

\section{REFERENCES}

Abdou, E.S., Nagy, K.S.A., Elsabee, M.Z., 2008. Extraction and characterization of chitin and chitosan from local sources. Bioresour. Technol. 99, 1359-1367.

Abdulkarim, A., Isa, M.T., Abdulsalam, S., Muhammad, A.J., Ameh, A.O., 2013. Extraction and characterisation of chitin and chitosan from mussel shell. Civ. Envir. Res., 3(2), 108-114.

Alsabagh, A.M., Elsabee, M.Z., Moustafa, Y.M., Elfky, A., Morsi, R.E., 2014. Corrosion inhibition efficiency of some hydrophobically modified chitosan surfactants in relation to their surface active properties. Egypt. J. Pet. 23 349-359.

Arbia, W., Arbia, L., Adour, L., Amrane, A., 2013. Chitin extraction from crustacean shells using biological methods - A review. Food Technol. Biotechnol. 51(1), 12-25.

Brugnerotto, J., Lizardi, J., Goycoolea, F.M., Arguelles-Monal, W., Desbrieres, J., Rinaudo, M., 2001. An infrared investigation in relation with chitin and chitosan characterization. Polymer 42, 3569-3580.

Chandumpai, A., Singhpibulporn, N., Faroongsarng, D., Sornprasit, P., 2004. Preparation and physico-chemical characterization of chitin and chitosan from the pens of the squid species, Loligo lessoniana and Loligo formosana. Carbohydr. Polym. 58, 467-474.

Cheng, S., Chen, S., Liu, T., Chang, X., Yin, Y., 2007. Carboxymenthylchitosan as an ecofriendly inhibitor for mild steel in $1 \mathrm{M}$ HCl. Mater. Lett. 61(14-15), 3276-3280.

Czechowska-Biskup, R., Jarosińska, D., Rokita, B., Ulański, P., Rosiak, J. M., 2012. Determination of degree of deacetylation of chitosan- Comparison of methods. Prog. Chem. Appl. Chitin and its... XVII, 5-20.

Dodane, V., Vilivalam, V.D., 1998. Pharmaceutical applications of chitosan. Pharm. Sci. Technol. Today 1, 246-253.

Du, Y., Zhao, Y., Dai, S., Yang, B., 2009. Preparation of water-soluble chitosan from shrimp shell and its antibacterial activity. Innov. Food Sci. Emerg. Technol. 10, 103-107.

FAO, 2009. Part 1: World review of fisheries and agriculture. The State of World Fisheries and Agriculture. 2010, 1-15.

Gámiz-González, M. A., Correia, D. M., Lanceros-Mendez, S., Sencadas, V., Gómez Ribelles, J. L., Vidaurre, A., 2017. Kinetic study of thermal degradation of chitosan as a function of deacetylation degree. Carbohydr. Polym. 167, 52-58.

Gooday, G. W., Jeuniaux, C., Muzzarelli, R., 1986. Chitin in nature and technology, Boston MA, Springer, pp. 469-476.

Gortari, M.C., Hours, R.A., 2013. Biotechnological processes for chitin recovery out of crustacean waste: A mini-review. Electron. J. Biotechnol. $16,12-25$.

Hajji, S., Younes, I., Ghorbel-Bellaaj, O., Hajji, R., Rinaudo, M., Nasri, M., Jellouli, K., 2014. Structural differences between chitin and chitosan extracted from three different marine sources. Int. J. Biol. Macromol. 65 298-306.

Horton, D., 2013. Advances in carbohydrate chemistry and biochemistry. Academic Press Imprint Elsevier Science \& Technology Books, San Diego, USA, First edition, Vol. 70.

Jang, M.-K., Kong, B.-G., Jeong, Y.-I., Lee, C. H., Nah, J.-W., 2004. Physicochemical characterization of $\alpha$-chitin, $\beta$-chitin, and $\gamma$-chitin separated from natural resources. J. Polym. Sci. Part Polym. Chem. 42, 3423-3432.

Kim, C. H., Choi, J. W., Chun, H. J., Choi, K. S., 1997. Synthesis of chitosan derivatives with quaternary ammonium salt and their antibacterial activity. Polym. Bull. 38, 387-393. 
Kim, S. K., 2010. Chitin, chitosan, oligosaccharides and their derivatives, biological activities and applications, CRC Press, London, New York.

Kim, S.-K., Rajapakse, N., 2005. Enzymatic production and biologica activities of chitosan oligosaccharides (COS): A review. Carbohydr. Polym. $62,357-368$

Lang, G., and Clausen, T., 1989. The use of chitosan in cosmetics. In Chitin and chitosan: Sources chemistry, biochemistry, physical properties and applications, Skjak-Braek G., Anthonsen T., and S. P. (Eds.) (pp.139- 147) Elsevier Sciences Publishers, London, New York.

Ma, Z., Wang, W., Wu, Y., He, Y., Wu, T., 2014. Oxidative degradation of chitosan to the low molecular water-soluble chitosan over peroxotungstate as chemical scissors. PLOS ONE. 9, 1-7.

No, H. K., Hur, E. Y., 1998. Control of foam formation by antifoam during demineralization of crustacean shell in preparation of chitin. J. Agric. Food Chem. 46, 3844-3846.

No, H. K., Young Park, N., Ho Lee, S., Meyers, S. P., 2002. Antibacterial activity of chitosans and chitosan oligomers with different molecular weights. Int. J. Food Microbiol. 74, 65-72.

Pepić, I., Hafner, A., Lovrić, J., Pirkić, B., Filipović-Grcić, J., 2010. A nonionic surfactant/chitosan micelle system in an innovative eye drop formulation. J. Pharm. Sci. 99, 4317-4325.

Percot, A., Viton, C., Domard, A., 2003. A characterization of shrimp shell deproteinization. Biomacromolecules. 4, 1380-1385.

Ramasamy, P., Subhapradha, N., Shanmugam, V., Shanmugam, A., 2014 Extraction, characterization and antioxidant property of chitosan from cuttlebone Sepia kobiensis (Hoyle 1885). Int. J. Biol. Macromol. 64, 202 212

Riszki, T. I., Harmami, H., 2015. Pengaruh suhu terhadap kualitas coating (pelapisan) stainless steel Tipe 304 dengan kitosan secara elektroforesis. Jurnal Sains dan Seni ITS 4, C17-C20.

Saleh, C. W., Harmami, H., Ulfin, I., 2017. Pengendalian korosi menggunakan inhibitor kitosan larut air untuk baja lunak dalam media $\mathrm{HCl} 1 \mathrm{M}$. Jurnal Sains dan Seni ITS 6, 1-4.

Truong, T., Hausler, R., Monette, F., Niquette, P., 2007. Fishery industrial waste valorization for the transformation of chitosan by hydrothermochemical method. Rev. Sci. Eau. 20, 253-262.

Vachoud, L., Pochat-Bohatier, C., Chakrabandhu, Y., Bouyer, D., David, L., 2012. Preparation and characterization of chitin hydrogels by water vapor induced gelation route. Int. J. Biol. Macromol. 51, 431-439.

Vargas, M., González-Martínez, C., 2010. Recent patents on food applications of chitosan. Recent Pat. Food Nutr. Agric. 2, 121-128.

Wasikiewicz, J.M., Yoshii, F., Nagasawa, N., Wach, R.A., Mitomo, H., 2005. Degradation of chitosan and sodium alginate by gamma radiation, sonochemical and ultraviolet methods. Radiat. Phys. Chem. 73, 287-295.

Younes, I., Rinaudo, M., 2015. Chitin and chitosan preparation from marine sources: Structure, properties and applications - Review. Mar. Drugs $13,1133-1174$

Zhao, X., Kong, A., Hou, Y., Shan, C., Ding, H., Shan, Y., 2009. An innovative method for oxidative degradation of chitosan with molecular oxygen catalyzed by metal phthalocyanine in neutral ionic liquid. Carbohydr. Res. 344, 2010-2013. 